REVIEW

\title{
Introduction to health economics for the medical practitioner
}

\section{P Kernick}

Postgrad Med J 2003;79:147-150

Against a background of increasing demands on limited resources, health economics is exerting an influence on decision making at all levels of health care. Health economics seeks to facilitate decision making by offering an explicit decision making framework based on the principle of efficiency. It is not the only consideration but it is an important one and practitioners will need to have an understanding of its basic principles and how it can impact on clinical decision making. This article reviews some of the basic principles of health economics and in particular economic evaluation.

Correspondence to: Dr D P Kernick, St Thomas' Medical Group, Cowick Street, Exeter EX4 1HJ, UK; su1838@eclipse.co.uk

Submitted 1 July 2002 Accepted

5 November 2002

\section{WHAT IS HEALTH ECONOMICS?}

Health economics is the discipline of economics applied to the topic of health care. Broadly defined, economics concerns how society allocates its resources among alternative uses. Scarcity of these resources provides the foundation of economic theory and from this starting point, three basic questions arise:

- What goods and services shall we produce?

- How shall we produce them?

- Who shall receive them?

Health economics addresses these questions primarily from the perspective of efficiencymaximising the benefits from available resources (or ensuring benefits gained exceed benefits forgone). Equity concerns are also recognisedwhat is a fair distribution of resources. Considerations of equity often conflict with efficiency directives. However, due to the contested nature of this area and the difficulties in quantifying equity dimensions, this element has not been a major focus of health economist's work.

\section{WHY IS HEALTH ECONOMICS \\ IMPORTANT?}

Thirty years ago there were limited options for doctors making treatment choices and patients did as they were told. Any values that contributed to the decision making process were implicit and determined by the physician. However, against a background of limited health care resources, an empowered consumer and an increasing array of intervention options (see fig 1 ) there is a need for decisions to be taken more openly and fairly.

The importance of the economic model is that it provides useful insights into how health care can be organised and financed and provides a framework to address a broad range of issues in an explicit and consistent manner. Organisational changes such as the development of the National Institute for Clinical Excellence and the devolution of decision making to primary care organisations have led to an increasing interest in the subject and its influence on health care organisation and decision making.

\section{WHAT DO HEALTH ECONOMISTS DO?}

Health economists are interested in the production of health at a number of levels. For example:

- What is health and how do we put a value on it?

- What influences health other than health care?

- What influences the demand for health care and health care seeking behaviour?

- What influences the supply of health care? (The behaviour of doctors and health care providers.)

- Alternative ways of production and delivery of health care.

- Planning, budgeting, and monitoring of health care.

- Economic evaluation-relating the costs and benefits of alternative ways of delivering health care.

Although all of these elements offer useful insights into the delivery of health care, it is economic evaluation that provides the bulk of health economists' work and is of most relevance to managers and practitioners. This exercise offers a framework for measuring, valuing, and comparing the costs (negative consequences) and benefits (positive consequences) of different health care interventions. In this way we can assess whether the benefits gained by introducing an intervention outweigh the benefits that are foregone. A discussion of economic evaluation and its principles forms the rest of this paper.

\section{CONCEPT OF ECONOMIC EVALUATION}

The concept of economic evaluation underpins efficiency choices in health care. ${ }^{1}$ It relates the benefits of alternative interventions to the resources incurred in their production (see fig 2 ).

We will first explore three principles that are an important part of any economic analysis before looking at the types of economic studies.

Abbreviations: GP, general practitioner; QALY, quality adjusted life year 

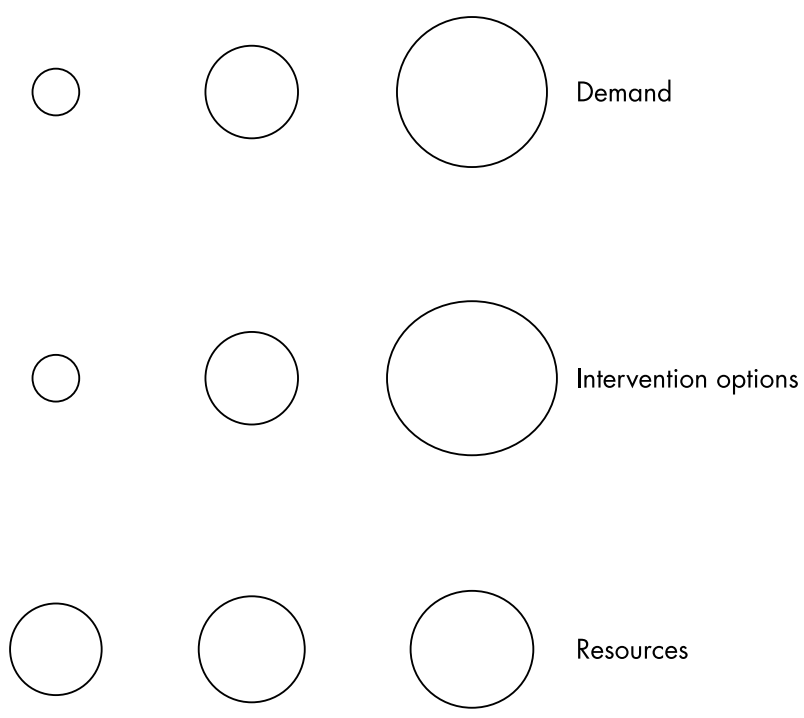

Resources

1970 s

1980 s

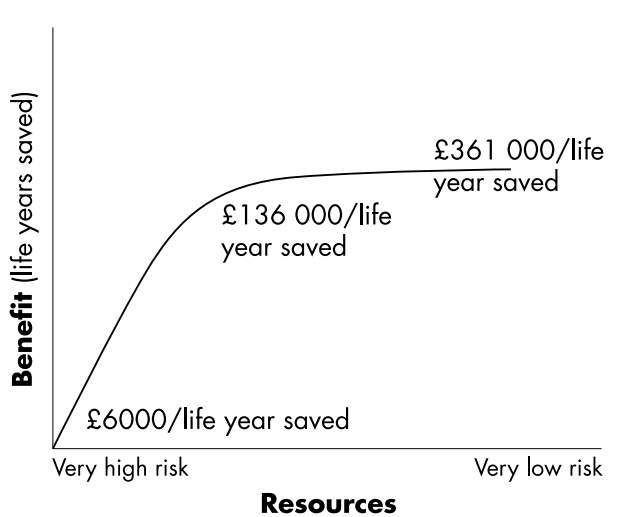

Figure 3 Costs and benefits in terms of life years saved from statin treatment. Costs/life years saved are shown for very high risk, low risk, and very low risk patients.

decisions in health are usually whether to expand or contract existing services, it is important to consider how increments in benefit change with increment in resource allocation and not the average benefits that are incurred by average costs. This is known as a marginal analysis. ${ }^{3}$

Figure 3 shows an example where the benefits in terms of years of life saved are plotted against resources invested in statin treatment. Three points are highlighted for cost/life year saved where resources are invested into very high risk, low risk, and very low risk patients. ${ }^{4}$

\section{WHAT ARE THE DIFFERENT TYPES OF ECONOMIC EVALUATION?}

We now explore the different types of economic evaluation which take their name from the way in which benefits are measured (see table 1).

\section{(1) Cost minimisation analysis}

In a cost minimisation analysis, the consequences of two or more interventions being compared are equivalent. The analysis therefore focuses on costs alone, and the cheapest option is chosen.

\section{(2) Cost effectiveness analysis}

Cost effectiveness analysis is the most common type of analysis and is used to compare drugs or programmes which have a common health outcome (for example, reduction in blood pressure, life years saved). ${ }^{5}$ Results are usually presented in the form of a ratio (for example, costs per life year gained). For example, it has been estimated that coronary care units cost $£ 4900$ per life year saved compared with neonatal intensive care units at $£ 11500$ per life year saved.

Often, intermediate or surrogate outcomes such as cases detected, reduction in cholesterol are measured and it is important to ensure that these intermediate measures have clinical meaning in terms of long term outcome for patients.

\section{(3) Cost utility analysis}

Often interventions impact both on quality and quantity of life. A cost utility analysis can be used to assess costs and benefits of interventions where there is no single outcome of interest and is useful comparing different programmes across different treatment areas. ${ }^{6}$

The most frequently used measure is the quality adjusted life year (QALY). Benefits are measured based on impact on length and quality of life to produce an overall index of health gain. A health state is valued between 0 (worst health) and 1 (best health) combined it with the length of time in that state. For example, a drug that yields an improvement in health state value of 0.6 over a period of 10 years would yield 6 
Table 1 The four types of formal economic evaluation

\begin{tabular}{|c|c|}
\hline Form of evaluation & $\begin{array}{l}\text { Measurement and valuation of } \\
\text { outcomes }\end{array}$ \\
\hline (1) Cost minimisation analysis & $\begin{array}{l}\text { Outcomes are assumed to be } \\
\text { equivalent. Focus of measurement } \\
\text { is on costs. Not often relevant as } \\
\text { outcomes are rarely equivalent }\end{array}$ \\
\hline (2) Cost effectiveness analysis & $\begin{array}{l}\text { Natural units (for example, life } \\
\text { years gained, deaths prevented) } \\
\text { that are common to competing } \\
\text { interventions. This approach } \\
\text { forms the bulk of published } \\
\text { studies and will be of most } \\
\text { relevance to practitioners }\end{array}$ \\
\hline (3) Cost utility analysis & $\begin{array}{l}\text { Health state values based on } \\
\text { individual preferences (for } \\
\text { example, quality adjusted life } \\
\text { years gained). An approach } \\
\text { which is gaining in importance } \\
\text { due to the need to decide } \\
\text { between different interventions at } \\
\text { a national level and the } \\
\text { importance placed on quality of } \\
\text { life. Many methodological } \\
\text { problems remain }\end{array}$ \\
\hline (4) Cost benefit analysis & $\begin{array}{l}\text { All outcomes valued in monetary } \\
\text { units (for example, valuation of } \\
\text { amount willing to pay to prevent } \\
\text { a death). Rarely used due to } \\
\text { methodological problems in } \\
\text { valuing all outcomes in monetary } \\
\text { terms }\end{array}$ \\
\hline
\end{tabular}

QALYs. It has been estimated that coronary artery bypass grafting costs $£ 2000$ per QALY compared with $£ 1100$ for hip replacement.

QALYs reflect people's preferences for different health states but their use remains contested in a number of areas.

When acting on the results of cost effectiveness and cost utility studies, if two treatments A and B are compared and costs are lower for $\mathrm{A}$ and outcomes better, then treatment $\mathrm{A}$ will be preferable. If, as is more commonly the case with a new drug, costs are higher for one treatment, but benefits are higher too, it is necessary to calculate how much extra benefits is obtained for the extra cost. A decision then needs to be made as to whether this addition in benefit is worth paying for. $^{7}$

Table 2 shows some tentative estimates of the cost/QALY of a range of interventions.

\section{(4) Cost benefit analysis}

In a Cost Benefit Analysis, attempts are made to value all the costs and consequences of an intervention in monetary terms. If the benefits are less than the costs then the intervention is acceptable. ${ }^{8}$ For example, a study of the impact of a triptan at a cost of $£ 4$ per attack in the treatment of migraine found an economic gain in terms of work absence saved of $€ 12.50 \mathrm{com}$ pared with placebo. ${ }^{9}$ However, the data requirements for this approach are often large and methodological issues around the valuation of non-monetary benefits such as lives saved makes this method problematic.

\section{(5) Cost consequences analysis}

Although this approach is not a formal method of economic analysis and as such is not shown in table 1 , it is one that may be more attractive to decision makers who can apply their own weight to the various outcomes. In some cases, studies consider many disparate outcomes that cannot be condensed
Table 2 A cost effectiveness league table. Cost per quality adjusted life year (QALY) of competing therapies - some tentative estimates

\begin{tabular}{|c|c|}
\hline Intervention & $\begin{array}{l}\text { Cost per } \\
\text { QALY (£, } \\
1990 \text { prices) }\end{array}$ \\
\hline GP advice to stop smoking & 270 \\
\hline Antihypertensive therapy & 940 \\
\hline Pacemaker insertion & 1100 \\
\hline Hip replacement & 1180 \\
\hline $\begin{array}{l}\text { Value replacement for aortic } \\
\text { stenosis }\end{array}$ & 1410 \\
\hline Coronary artery bypass graft & 2090 \\
\hline Kidney transplant & 4710 \\
\hline Breast screening & 5780 \\
\hline Heart transplant & 7840 \\
\hline Hospital haemodialysis & 21970 \\
\hline
\end{tabular}

Table 3 An example of a cost consequence study-transferring gastroscopy services to primary care

\begin{tabular}{|c|c|}
\hline Costs & $\begin{array}{l}\text { Consequences } \\
\text { (benefits/dysbenefits) }\end{array}$ \\
\hline $\begin{array}{l}\text { GP and nurse (what activity is } \\
\text { being given up by these } \\
\text { practitioners to undertake the new } \\
\text { service) }\end{array}$ & Health state \\
\hline $\begin{array}{l}\text { Saving in hospital resources (what } \\
\text { is being released and how is it } \\
\text { being utilised?) }\end{array}$ & Diagnostic accuracy \\
\hline $\begin{array}{l}\text { Capital costs, for example, new } \\
\text { buildings, equipment }\end{array}$ & $\begin{array}{l}\text { Patient satisfaction (better access, } \\
\text { shorter waiting times, } \\
\text { understanding of condition) }\end{array}$ \\
\hline Patient costs & $\begin{array}{l}\text { Patient dissatisfaction (lack of } \\
\text { expert care) }\end{array}$ \\
\hline $\begin{array}{l}\text { Costs of administering primary } \\
\text { care service including quality } \\
\text { control }\end{array}$ & $\begin{array}{l}\text { Loss of opportunities for } \\
\text { secondary care training }\end{array}$ \\
\hline
\end{tabular}

into a single measure of benefit. ${ }^{10}$ In this case, costs and outcomes are presented in a disaggregated form, which avoids the need to represent results as a single index but which makes decision-making more difficult. Never the less it is an approach which reflects how decisions are made in the real world. Table 3 shows how a cost consequence study might look in practice.

\section{A PRACTICAL EXAMPLE-TREATING RAISED CHOLESTEROL WITH STATINS}

We conclude with a practical example demonstrating how health economics can facilitate a health care decision. Table 4 shows the cost effectiveness of treating raised cholesterol with statins at various levels of population risk. ${ }^{11}$ How can we decide what risk should be targeted?

Table 5 shows some possible alternative uses of our money. Using the principle of opportunity cost we can get some sort of idea of what we would have to forego for treating each level of risk. Clearly there are many other issues to be taken into consideration but this information can help to frame the decision.

However, it should be born in mind that economic analysis focuses on efficiency which does not necessarily correlate with affordability. Pickin used existing data to calculate the cost of 
Table 4 Cost effectiveness of treating patients with raised cholesterol at differing annual risks of an event

\begin{tabular}{ll}
\hline $\begin{array}{l}\text { Annual risk of } \\
\text { cardiovascular event } \\
(\%)\end{array}$ & $\begin{array}{l}\text { Cost/life year saved } \\
(£)\end{array}$ \\
\hline 4.5 & 5100 \\
3 & 8200 \\
2 & 10700 \\
1.5 & 12500 \\
\hline
\end{tabular}

Table 5 Estimates of the cost effectiveness of some competing interventions

\begin{tabular}{ll}
\hline Intervention & $\begin{array}{l}\text { Cost/life year saved } \\
(£)\end{array}$ \\
\hline Blood pressure reduction & 1000 \\
Counselling for activity & 3000 \\
Coronary care units & 4900 \\
Breast screening & 8400 \\
Cervical screening & 9000 \\
Neonatal intensive care & 11500 \\
Haemodialysis & 27000 \\
\hline
\end{tabular}

Table 6 Affordability of treating raised cholesterol-implications for a typical health authority of treating raised cholesterol

\begin{tabular}{lll}
\hline $\begin{array}{l}\text { Annual risk of } \\
\text { cardiovascular event (\%) }\end{array}$ & $\begin{array}{l}\text { No needing treatment } \\
\text { (\% population) }\end{array}$ & $\begin{array}{l}\text { Cost (£ } \\
\text { million) }\end{array}$ \\
\hline 4.5 & 5.1 & 459 \\
3 & 8.2 & 885 \\
2 & 15.8 & 1712 \\
1.5 & 24.7 & 2673 \\
\hline
\end{tabular}

treating the population with statins at different levels of risk. Table 6 shows the number of the population needed to treat for each risk level and the cost. Although treating the population who have a $2 \%$ risk would be efficient in terms of cost/life year saved when compared to other interventions, it would consume an unacceptable proportion of our resources.

\section{Key references}

- Kernick D. Getting health economics into practice. Abing don: Radcliffe Press, 2002.

- Jefferson T. Elementary economic evaluation. London: BM Books, 2000

- Donaldson C. Evidence based health economics. London: BMU Books, 2002.

- The BMU Health Economics Collection: www.bmi.com/cgi/ collection/health economics.

- The NHS Health Technology Assessment Programme: www.ncchta.org. Contains some excellent monographs on areas of health economics that are considered in some depth but remain accessible. Can be downloaded directly from the web.

- The NHS Economic Evaluation Database: www.york.ac.uk/nhsdhp. A comprehensive database of all economic evaluations that are published.

\section{CONCLUSION}

Difficult choices in health care are inevitable and there is an increasing emphasis on making decisions explicit and fair. Health economics suffers from a number of methodological limitations but it can offer us useful concepts and principles which help us think more clearly about the implications of resource decisions we make. An understanding of some basic economic principles is essential for all practitioners not only to understand the useful concepts the discipline can offer but to appreciate its limitations and shortcomings.

\section{REFERENCES}

1 Drummond M. Economic analysis alongside control trials. London: Department of Health, March 1994.

2 Kernick D. Costing principles in primary care. Fam Pract 2000;17:1766-70.

3 Torgerson DJ, Spencer A. Marginal costs and benefits. BM 1996;312:35-6.

4 Pharoah P, Hollingworth W. Cost effectiveness of lowering cholesterol concentration with statins in patients with and without existing coronary heart disease. BM 1996;312:1443-8.

5 Robinson R. Cost effective analysis. BMU 1993:307:793-5.

6 Robinson R. Cost utility analysis. BN 1993;307:859-62.

7 Drummond M, Maynard A. Purchasing and providing cost effective health care. London: Churchill Livingstone, 1993.

8 Robinson R. Cost benefit analysis. BM 1993;307:924-6.

9 Wells NE, Steiner TJ. Effectiveness of eletriptan in reducing time loss caused by migraine attacks. Pharmacoeconomics 2001:18:557-66.

10 Mauskopf J, Paul J, Grant D, et al. The role of cost consequence analysis in health care decision making. Pharmacoeconomics 1998; 13:277-88

11 Pickin D, McCabe C, Ramsey L, et al. Cost effectiveness of statin treatment related to the risk of coronary heart disease and cost of drug treatment. Heart 1999:82:325-32. 